\title{
UNDER THE INFLUENCE: AN EXAMINATION OF THE TACTICS PhaRmaceutical CoMPanies USE to Manipulate Physicians
}

\author{
Shena T. Wheeler
}

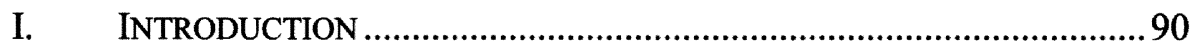

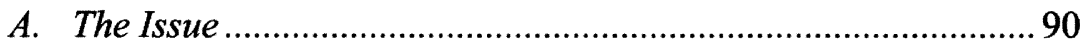

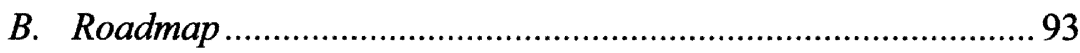

II. BACKGROUND: STATE AND FEDERAL LEGISLATION LIMITING PHARMACEUTICAL COMPANY ADVERTISING EXPENDITURES AND GIFTS TO PHYSICIANS FROM PHARMACEUTICAL COMPANIES ..........93

A. Massachusetts: A Total Ban..................................................... 93

B. Minnesota: Partial Ban with Recordkeeping Requirements and Several Notable Exceptions ....................................................... 95

C. New York: A Proposal Lawmakers Can't Refuse? .................... 97

D. Vermont, West Virginia, District of Columbia, and Maine: Big Brother is Watching ................................................................ 98

E. Proposed Federal Legislation: Is it Enough?........................ 100

III. BACKGROUND: AMERICAN MEDICAL ASSOCIATION STANDARDS FOR PHYSICIAN GIFTS, FOOD \& DRUG ADMINISTRATION STANDARDS FOR ADVERTISING, AND INDIANA STATE MEDICAL

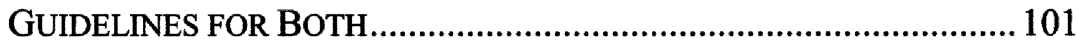

A. American Medical Association Standards ................................ 101

B. Food and Drug Administration Limitations: An Historical Perspective

C. Indiana State Medical Association Compliance and Guidance 103

IV: ANALYSIS: DO LIMITS AND BANS ON PHYSICIAN GIFTS AND ADVERTISING HELP OR HURT PATIENTS? .......................................... 103

A. What Effect do Gifts have on Physicians' Prescribing Habits? 104

B. Are Pharmaceutical Representatives Qualified to Educate Doctors about New Drugs? ....................................................... 106

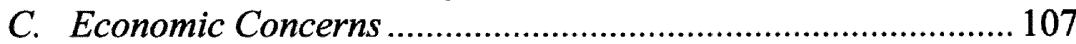

D. Does Banning Free Drug Samples Hurt Patients?.................. 109



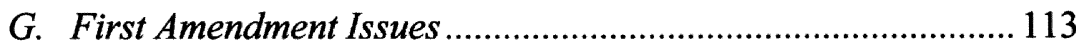

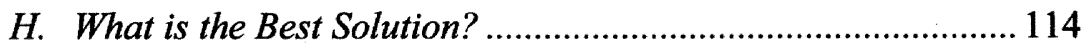

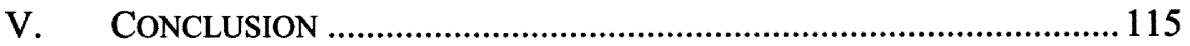

* J.D. Candidate, 2010, Indiana University School of Law - Indianapolis; B.S., 2005, Central Michigan University 


\section{INTRODUCTION}

Marie Fishel has some deep regrets: while celebrating her twentyfifth wedding anniversary last night, she inhaled five plates of baby-back ribs at the local steakhouse's All-You-Can-Eat Ribs Monday. As a result, Marie's persistent heartburn is flaring up again. In the past, over-thecounter medications, such as Prilosec, Pepcid AC, and Pepto Bismol, have not relieved her symptoms. Frustrated, Marie made an appointment with her family physician. As she swings her feet from the examination table in the doctor's office, internally rehearsing a list of her symptoms and their longevity for when the doctor shows up, she looks around the examination room, hoping to distract her mind from the painful burning in her esophagus. Prominently featured on the wall are posters of a human digestive tract, sponsored by Nexium. Bored with the graphic representation of her small intestine, she reaches for the remote control to the exam room's tiny television set. In between Kathie Lee Gifford and Hoda Kotb's pleasantries about the latest thigh cream, she is bombarded with commercials for prescription drugs. As the wait grows increasingly painful, she reaches for this week's People magazine, with a smiling Patrick Swayze on its cover. Between gossip tidbits and human interest stories, Marie notices glossy pages with columns in tiny typeface, touting the benefits and risks of everything from birth control pills to blood pressure medication. By the time the physician enters, carrying a Cymbalta clipboard, with a menagerie of drugname inscribed ink pens in her lab coat pocket, Marie cannot help but wonder who is really prescribing her medication - her physician or the pharmaceutical companies?

While Marie's fictional situation has been embellished for dramatic effect, concerns about pharmaceutical companies' gifts to physicians and pharmaceutical advertisements are far from fictional and are creating quite a buzz in both the medical and legal professions. As lawmakers and industry watchdogs create new regulations in hopes of increasing pharmaceutical company accountability and decreasing prescription drug costs, there is an increasing need to examine the risks and benefits of such regulations.

\section{A. The Issue}

Pharmaceutical companies strive to create and maintain relationships with physicians through advertising and gift-giving, in hopes of influencing them to prescribe their drugs more frequently than their competitors. ${ }^{1}$ According to a survey published in the New England Journal of Medicine in $2007,94 \%$ of physicians reported having a relationship with pharmaceutical

1. Eric G. Campbell et al., A National Survey of Physician-Industry Relationships, 356 New ENG. J. MED. 1742, 1743 (2007). 
companies. ${ }^{2}$ Of those physicians, $83 \%$ claimed that those relationships involved free meals, while $78 \%$ of those physicians received free drug samples. $^{3} \quad$ Other types of gifts include trinkets, honors for speaking engagements, reimbursement of travel expenses, and free admission to entertainment events or medical conferences. 4

Recently, several states have proposed or adopted total or partial bans on gifts made by pharmaceutical companies to physicians. ${ }^{5}$ Most of these statutes include disclosure requirements for advertising expenditures made by pharmaceutical companies. ${ }^{6}$ Although the definition varies state-bystate, advertising expenditures typically include gifts given over a certain dollar threshold made to physicians. ${ }^{7}$ Legislation has also been introduced in the United States Congress which would require pharmaceutical companies to report all "payment[s] or transfer[s] of value" made to physicians. 8 Medical schools across the country have also adopted this trend, restricting gifts made by pharmaceutical companies to their students. 9

In addition, the Pharmaceutical Research and Manufacturers of America (PhRMA) recently released voluntary guidelines prohibiting pharmaceutical companies from offering physicians trinkets such as pens, notepads, and calendars emblazoned with a drug name. ${ }^{10}$ Under these guidelines, small gifts lacking any educational purpose and that are valued under $\$ 100$ are prohibited. ${ }^{11}$

Both physicians and patients can be affected by drug advertisements paid for by pharmaceutical companies. ${ }^{12}$ Pharmaceutical companies spend nearly twice as much on advertising and marketing as on pharmaceutical

2. Id. at 1742 .

3. Id.

4. Id. at 1743.

5. VT. STAT. ANN. tit. $18, \S 4632$ (2008); MINN. STAT. ANN. $\S 151.461$ (West 2008).

6. Id.

7. Id.

8. Physician Payments Sunshine Act of 2007, S.2029, 110th Cong. (2007).

9. For example, the University of Pennsylvania, Stanford University, Yale University, and the University of Maryland medical schools all prohibit pharmaceutical company gift-giving on their campuses. Johns Hopkins University School of Medicine was considering a ban as recently as March 2009. The University of Minnesota is considering a "conflict-of-interest policy" that would have effects similar to that of a gift ban. See generally, Julekha Dash, Johns Hopkins University Eyeing Ban on Drug Industry's Free Pens, Food, and Fun, Boston BUS. J., Mar. 6, 2009, available at http:/boston.bizjournals.com/boston/ othercities/baltimore/stories/2009/03/09/story3.html?b=1236571200\%5E1789736; Janet Moore, U Medical School Plan: Ban All Gifts to Doctors, STAR TrIB.-Oct. 21, 2008, available at http://www.startribune.com/lifestyle/health/31435329.html?elr=KArksLckD8EQDUoaEyqy P4O:DW3ckUiD3aPc:Yyc:aUUJ.

10. Mary Ellen Schneider, Voluntary PhRMA Guidelines will Ban Trinkets, ENTREPRENEUR, (October 2008), http://www.entrepreneur.com/tradejournals/article/18894 3082.html.

11. Id.

12. Matthew Arnold, Consumer Ads Influence Doctors: Study, MED. MARKETING \& MEDIA, (June 2005), http://findarticles.com/p/articles/mi_qa5351/is_200506/ai_n21373090. 
research and development; this includes the aforementioned gifts and free samples, as well as advertisements peppering primetime television and four-page spreads in glossy magazines. ${ }^{13}$ There is evidence that patientdirected advertisements impact physicians as well. ${ }^{14}$ One study found that doctors are discussing advertisements with their patients more than ever before. $^{15}$ That same study found that physicians mention these ads to their patients just as often as their patients ask their doctors about the ads. ${ }^{16}$ When pharmaceutical advertising began, it was directed solely at prescribing physicians; advertisements were directed to consumer-patients for the first time in $1981 .^{17}$ Since then, there has been an influx of consumerpatient-directed pharmaceutical advertisements on television, on the radio, and in magazines. This is important because although the target audience for these ads consists of consumer-patients, physicians will inevitably be exposed to them as well, which will likely influence their prescribing habits.

In Indiana, a state which serves as home to many pharmaceutical companies, ${ }^{18}$ there has been some progress in this area of the law. After being the first pharmaceutical company in the nation to endorse the Physician Payments Sunshine Act (PPSA), ${ }^{19}$ Eli Lilly and Company plans to launch an online registry of its payments to physicians in $2009 .{ }^{20}$ Lilly would create a database accessible to the public via the Internet, which, by 2011, would include all payments made to physicians, and payments made for speaking engagements, bringing it into anticipatory compliance with the PPSA, should it be passed by Congress. ${ }^{21}$ Despite Lilly's voluntary anticipatory compliance with the PPSA, it is not currently held to any state requirements: The Indiana state legislature, unlike some other states, has yet

13. York University, Big Pharma Spends More On Advertising Than Research And Development, Study Finds, SCI. DAILY (Jan. 7, 2008), http://www.sciencedaily.com/releases/ 2008/01/080105140107.htm.

14. Arnold, supra note 12.

15. Id.

16. Id.

17. Francis B. Palumbo, and C. Daniel Mullins, The Development of Direct-toConsumer Prescription Drug Advertising Regulation, 57 FoOD \& DRUG L.J. 423, 424 (2002).

18. Indiana's pharmaceutical companies include, but are not limited to, Bayer, Bristol Mayer Squibb, Eli Lilly \& Co., Covance, Pfizer, and Schwarz Pharma. Pharmaceutical Companies in Indiana, http://www.purdue.edu/dp/ptec/companies.pdf.

19. The Physician Payments Sunshine Act, so named because of its intention to shed light on payments from pharmaceutical companies to physicians, is proposed Federal legislation. If passed, it would require pharmaceutical companies to issue quarterly reports for most categories of physician gifts. It does not, however, purport to ban physician gifts altogether. Physician Payments Sunshine Act of 2007, S.2029, 110th Cong. (2007).

20. Erik Greb, Lilly to Establish Registry of Its Payments to Physicians, THE Electronic Newsl. OF Pharmaceutical Tech. (Oct. 2, 2008), http:// pharmtech.findpharma.com/pharmtech/Manufacturing/Lilly-to-Establish-Registry-of-its-Payments-toPhy/ArticleStandard/Article/detail/555701?contextCategoryld=40939\&ref=25.

21. Id. 
to introduce legislation banning or partially banning gifts to physicians.

\section{B. Roadmap}

This Note discusses external factors influencing physicians' prescribing habits, including gifts from pharmaceutical companies and drug advertisements, and the current and pending state and federal regulations designed to curb such practices. In order to foster an understanding of the current legislation, Section II provides a historical background of several state statutes and federal legislation regulating physician gifts, including motivation and criticisms of each. Section III offers historical background of drug advertising regulations nationwide, with a special focus on such regulations in Indiana. Section IV discusses whether current and pending bans on physician gifts help or hurt consumer-patients and contains an analysis of gifts from pharmaceutical companies and drug advertising in light of the current economic crisis and the state of America's health care system. Finally, Section V concludes the discussion with the suggestion that achieving a balance between accurate dissemination of information about new drugs and therapies and limits on undue influence from pharmaceutical companies may be the best way to resolve the issue.

\section{BACKGROUND: STATE AND FEDERAL LEGISLATION LIMITING PHARMACEUTICAL COMPANY ADVERTISING EXPENDITURES AND GIFTS TO PHYSICIANS FROM PHARMACEUTICAL COMPANIES}

In order to facilitate a better understanding of the necessity of state and federal legislation regulating physician gifts, a discussion of the current and pending state and federal legislation is imperative. The state statutes can be placed into three broad categories: 1) total bans on physician gifts; 2) partial bans on physician gifts; and 3) required recordkeeping of all advertising costs, including physician gifts, with disclosure to the state government.

\section{A. Massachusetts: A Total Ban}

Massachusetts is the only state thus far to prohibit all gifts made by pharmaceutical companies to physicians. ${ }^{22}$ The ban, introduced by Senate President Therese Murray in March 2008, is the first of its kind in the United States. ${ }^{23}$ It allows for fines of up to $\$ 5,000$ for a single infraction. ${ }^{24}$

22. MASS. Gen. LAWS ANN. ch. $111 \mathrm{~N}, \S 2$ (West 2008).

23. Megan Woolhouse, Ban on Gifts to Doctors Sought, Boston GloBe, Mar. 4, 2008, available at $\mathrm{http} / / / \mathrm{www}$. boston.com/news/health/articles/2008/03/04/ban_on_gifts_to_doctors_ sought/

24. Id. 
Touted as an "Act to promote cost containment, transparency and efficiency in the delivery of quality health care," 25 the Massachusetts statute was passed in August 2008 and became effective on January $1,2009{ }^{26}$ It requires the Massachusetts Department of Health to "adopt a standard marketing code of conduct for all pharmaceutical or medical device manufacturing companies that employ a person to sell or market prescription drugs or medical devices in the commonwealth." 27 In turn, the new code created by the Department of Health must, by law, prohibit meals bought for physicians by pharmaceutical companies for entertainment, absent informational presentations, outside the physician's office, or for the physician's spouse. ${ }^{28}$ In addition, it must prohibits gifts of tickets for sporting events or leisure activities; reimbursement for travel expenses; compensation for a physician's participation in a continuing medical education (CME) presentation; meals at conferences; cash payments, unless for services; and grants or scholarships related to the prescription drug. ${ }^{29}$ However, the new code allows for an exchange of academic or scientific information; purchase of ad space in academic journals; drug samples; payment for participation in clinical trials; and reimbursement for expenses relating to technical training on use of a medical device. ${ }^{30}$ These specific prohibitions and requirements demonstrate the state's balancing act: outlaw unnecessary and frivolous gifts and payments to physicians while fostering the need to disseminate information related to new drugs and therapies. The Massachusetts statute allows a pharmaceutical company to educate physicians on its new drug innovations, but draws the line at social means and compensation for attendance at various $\mathrm{CME}$ events.

Critics of the ban cite concerns about disrupting the free flow of drug information between drug companies, physicians, and patients. They assert that pharmaceutical company representatives are experts regarding the drugs they sell. ${ }^{31}$ Although there are concerns that physician gifts raise prescription drug costs, at least one critic of the Massachusetts statute, Julie Corcoran, deputy vice president of PhRMA, says there is no evidence to support such a contention. 32

Other critics of the Massachusetts statute have expressed concern that the ban will suppress drug innovation and investment in the state. ${ }^{33}$ Eli Lil-

25. Massachusetts S.B. No. 2863 (Mass. 2008).

26. MaSS. GeN. LAWS ANN. ch. $111 \mathrm{~N}$, § 2 (2008).

27. Id.

28. $I d$.

29. Id.

30. $I d$.

31. Woolhouse, supra note 23.

32. $I d$.

33. Mark Hollmer, Eli Lilly CEO says Gifts Ban could Drive Drug Research from Massachusetts, BosTON BUS. J.,Sept. 19, 2008, available at http://www.bizjournals.com/ boston/stories/2008/09/15/daily78.html (last visited Jul. 8, 2009). 
ly president and CEO John Lechleiter noted the ban has "the potential not only to stifle clinical research in Massachusetts, but also to complicate a key part of market access: the ability to share information." 34 Lechleiter fears the law will "subject doctors, hospitals and academic institutions to complex financial disclosure requirements about payments for clinical research." ${ }^{35}$ These rising administrative costs may even parlay into increased prescription drug costs. Thomas Sullivan, president of a medical communications company, argued that the ban would have "devastating effects on the research institutions that make Boston the largest healthcare economy in the country." ${ }^{36}$ Sullivan estimates that the ban "could disqualify as many as $20 \%$ of our faculty, as the ban covers all honorarium and travel ... we would have no way to pay speakers from Massachusetts to travel to events, and no way to pay them for their time. ${ }^{37}$ However, the ban has not been in effect long enough to determine the legitimacy of these concerns.

\section{B. Minnesota: Partial Ban with Recordkeeping Requirements and Several Notable Exceptions}

Minnesota legislators passed a partial ban on physician gifts in $2008 .^{38}$ In Minnesota, pharmaceutical companies are prohibited from giving any gifts to any physician with a "combined retail value" exceeding $\$ 50$, subject to a few exceptions. ${ }^{39}$ The exceptions include: drug samples; compensation to sponsor medical conferences, as long as the compensation is not paid to the physician and the conference is for educational purposes only; consulting fees for research projects; publications; employee salaries; and "reasonable honoraria and payment of the reasonable expenses of a practitioner who serves on the faculty at a professional or educational conference or meeting." 40

However, public availability to such information is limited. Public accessibility is provided, but practically speaking, it is very difficult to obtain any of the disclosure reports. ${ }^{41}$ The disclosure forms are unavailable electronically or online.. ${ }^{42}$ The only way for an individual to obtain the forms is to "travel to the state office in Minnesota in order to photocopy

34. Id.

35. Id.

36. Ben Comer, State Senate Approves Ban on Gifts to Physicians, MEd. MARKETING \& MEDIA (Apr. 21, 2008), available at $\mathrm{http}: / / \mathrm{www} . \mathrm{mmm}$-online.com/State-Senate-approvesban-on-gifts-to-physicians/article/109220/.

37. Id.

38. MinN. Stat. ANN. § 151.461 (2008).

39. Id.

40. Id.

41. Robert Kirby, Karl H. Buch, \& Phoebe A. Wilkinson, N.Y. Seeks to Join States Regulating Pay to Physicians, OUTSIDE COUNS., 240 N.Y.L.J. 4, 4 (2008).

42. Id. 
each form at a fee of $\$ 0.25$ per copy." 43 This restricts public availability to those unable to travel to the state office; public access is therefore somewhat illusory.

Dr. Carl Heltne, chief medical officer for SMDC Health System of Duluth, Minnesota, a nonprofit health care system of over twenty clinics and hospitals, supports the ban because he feels it stifles misconceptions about the medical industry: "No matter how you look at it, we [are] all influenced by these marketing activities ... [b]ut patients come to us and they trust us to make decisions solely on their behalf. To uphold that trust, we can[not] have even a perception that companies influence us." ${ }^{, 44}$ Minnesota's ban on pharmaceutical companies' gifts of free food for physicians was the first of its kind. ${ }^{45}$ Interestingly, after the ban went into effect, pharmaceutical companies began inviting nurses and secretaries to informational dinners, despite the fact that nurses and secretaries lack prescription authority. ${ }^{46}$ However, the real targets of the pharmaceutical company's marketing blitz are the speakers at the dinners, physicians who require training about the company's drug prior to each speaking engagement. ${ }^{47}$ The doctors are often paid handsomely for these presentations, some fetching up to $\$ 100,000$ per year. ${ }^{48}$ However, most claim to be immune from the influence of compensation they earn from the presentations. 49

After watchdog groups first raised awareness about the Minnesota law in 2007, pharmaceutical companies began spending less on Minnesota doctors. $^{50}$ From 2007 to 2008 , pharmaceutical company payments to doctors dropped by over $\$ 3.5$ million. ${ }^{51}$ This drop could be attributed to the increasing transparency of pharmaceutical company payments to physicians, but it could also be a result of a suffering economy. ${ }^{52}$ While the reason for the decline is unclear, others suggest that increasing concern over the conflict of interest between pharmaceutical companies and doctors is a plausible explanation. ${ }^{53}$

43. Id. (citing Joseph S. Ross et al., Pharmaceutical Company Payments to Physicians: Early Experiences with Disclosure Laws in Vermont and Minnesota, 297 JAMA $1216,1218(2007))$.

44. Gardiner Harris, Minnesota Limits on Gifts to Doctors May Catch On, N. Y. TIMES, Oct. 12, 2007, available at http://www.nytimes.com/2007/10/12/us/12gift.html.

45. Id.

46. Id.

47. Id.

48. Id.

49. Id.

50. Jeremy Olson, Pharmaceutical Companies Spending Less on Minnesota Doctors, The PIONEer Press, Jul. 6, 2009, available at http:/www.twincities.com/ci_12573822 ?nclick check=1.

5i. Id.

52. Id.

53. Id. 


\section{New York: A Proposal Lawmakers Can't Refuse?}

In 2008, a statute that would partially limit gifts to physicians was introduced in the New York Assembly. The New York Assembly Bill cited

compelling evidence that the vast majority of physicians accept some type of gift or payment from pharmaceutical and medical device manufacturers, and often such gifts and payments, even when of little value, influence physicians to prescribe treatments that are more expensive and no more effective or safe, and are sometimes less effective and more dangerous, than other available treatments. ${ }^{54}$

The New York Assembly also found that "[l] egislation is necessary to prohibit presenters at continuing professional education programs from providing false or misleading information to prescribers and to require all potential conflicts of interest be disclosed to attendees of such programs." The proposed legislation would prohibit all gifts aggregating to more than $\$ 50$ annually to physicians and medical students, with exceptions: drug samples; payment for clinical trials; manufacturer's discounts for drugs or medical devices; and "anything of economic value given by a person with a financial relationship with a manufacturer who is related by blood, marriage or adoption within three degrees of consanguinity to the recipient prescriber."56 The proposed New York legislation differs from the Minnesota statute because it applies to both physician gifts and to gifts made to medical students. $^{57}$ The permissible exceptions also differ: For example, the Minnesota statute provides exceptions for publications and employee salaries, while the proposed New York statute does not. ${ }^{58}$ These small differences in state-by-state legislation may provide a better framework for possible federal legislation banning physician gifts, since they permit lawmakers, pharmaceutical companies, and physicians to see what works and what does not. A federal model would likely take these findings into consideration.

The proposed New York legislation also requires yearly disclosure of any benefits given or received. ${ }^{59}$ The disclosure is mandatory when the physician or medical student "offered, gave, or received a benefit," the pharmaceutical company gave the physician a discount, or there was "a fi-

54. Id.

55. Id.

56. S. 6015, 64th Gen. Assem., 231st Sess. (N.Y. 2009).

57. Id.

58. Compare MinN. STAT. ANN. $\S 151.461$ (2008) with S. 6015, \# Gen. Assem., 231st Sess. (N.Y. 2009).

59. S. 6015, 64th Gen. Assem., 231st Sess. (N.Y. 2009). 
nancial relationship" between the pharmaceutical company and the physician or medical student. ${ }^{60}$ If one of these factors is met, a disclosure must be made in one of three categories: Disclosure of a Benefit, Disclosure of a Discount, or Disclosure of a Financial Relationship. ${ }^{61}$ Violation of the partial gift ban or failure to comply with the disclosure requirements could result in a fine of $\$ 5,000-\$ 50,000$ for pharmaceutical companies, or $\$ 5,000$ $\$ 10,000$ for physicians. ${ }^{62}$

\section{Vermont, West Virginia, District of Columbia, and Maine: Big Brother is Watching}

The least restrictive state statutes require disclosure of physician gifts. In 2008, Vermont legislators passed an initiative requiring disclosure of marketing expenditures, including physician gifts. ${ }^{63}$ The Vermont statute requires pharmaceutical companies to record gifts made to physicians if the value of the particular gift exceeds $\$ 25$, subject to a civil penalty of up to $\$ 10,000$ for failure to disclose. ${ }^{64}$ Along with gifts under $\$ 25$, drug samples, scholarships to medical students, and drug rebates are also exempt. ${ }^{65}$ After reports are made to the attorney general, the disclosures are then reported to state lawmakers and the governor. ${ }^{66}$ Another important exemption from such reports is any statement which would disclose a pharmaceutical company's trade secrets. ${ }^{67}$ As a result, "61 percent of payments to physicians that had been disclosed under the Vermont law were designated 'trade secrets' by the reporting manufacturer, and were therefore kept confidential from the public." 68

West Virginia also requires disclosure of marketing expenditures associated with prescription drugs, excluding drug samples, reimbursement for costs associated with clinical trials, and scholarships for medical students. ${ }^{69}$ As the least restrictive state statute for pharmaceutical companies, West Virginia's statute does not apply to medical device manufacturers. ${ }^{70}$ The disclosure information is not available to the public: "Any 'national aggregate expense [information]' disclosed to state officials is considered

60. Id. "Financial relationship" is defined by the proposed statute as "an ownership interest, investment interest, or compensation arrangement."

61. Id.

62. Id.

63. VT. Stat. AnN. tit. 18, § 4632 (2008).

64. Id.

65. $I d$.

66. $I d$.

67. Kirby, supra note 41.

68. Id. (citing Joseph S. Ross et al., Pharmaceutical Company Payments to Physicians: Early Experiences with Disclosure Laws in Vermont and Minnesota, 297 JAMA $1216,1218(2007))$.

69. W. VA. CODE $\S 5 A-3 C-13$ (2008).

70. Kirby, supra note 41 . 
confidential and is not subject to release under West Virginia's Freedom of Information Act." 71 In addition, the West Virginia statute does not incentivize pharmaceutical companies to comply with the law because there are no penalties levied for failure to do so. ${ }^{72}$

Critics of the West Virginia statute, including some pharmaceutical companies, allege that it may violate the First Amendment of the United States Constitution; since the "communication [is] made for the sole purpose of selling products or services," the speech should be protected under the commercial speech doctrine. ${ }^{73}$ It may also be seen as a violation of Free Speech because the information, released in aggregate, may reflect poorly upon a pharmaceutical company and "discourage the public" from purchasing its products. ${ }^{74}$

The District of Columbia's statute simply requires a reporting of all advertising costs made by pharmaceutical companies. ${ }^{75}$ Legislation in Maine, however, is considerably more complicated. The Maine statute requires "manufacturers or labelers" of prescription drugs to report their advertising expenses annually. ${ }^{76}$ Advertising expenses include direct expenditures for television, radio, and print ads, gifts to physicians over $\$ 25$ in value, and travel expenses. It also includes drug samples, if those samples will not be given to patients for free. ${ }^{77}$ Exclusions include expenses of $\$ 25$ or less; "reasonable compensation and reimbursement for expenses in connection with a bona fide clinical trial of a new vaccine, therapy or treatment," and educational scholarships. ${ }^{78}$ The statute's stated purpose is to "enabl[e] [Maine] to determine the scope of prescription drug marketing costs and their effect on the cost, utilization and delivery of health care services and further[ ] the role of this State as guardian of the public interest."79

A similar Maine statute was challenged in IMS Health Corp. $v$. Rowe $^{80}$ Prescription Drug Information Intermediaries (PDIIs) intercept valuable information regarding pharmaceutical companies, physicians, and patients, including prescribing pattern information. They later sell such information back to pharmaceutical companies, who in turn use it to advance their market research practices. ${ }^{81}$ The court weighed several advan-

71. Id.

72. Id.

73. Brienne Taylor Greiner, A Tough Pill to Swallow: Does the First Amendment Prohibit WV from Regulating Pharmaceutical Companies' Advertising Expenses to Lower the Cost of Prescription Drugs? 109 W.VA. L. REV. 107, 119-20 (2006).

74. Id.

75. D.C. CODE § 48-833.01 (2008).

76. ME. Rev. STAT. ANN. tit. 22, § 2698-A (2008).

77. Id.

78. Id.

79. Id.

80. IMS Health Corp. v. Rowe, 532 F.Supp.2d 153, 154 (D. Me. 2007).

81. Id. at 158 . 
tages and disadvantages of such PDIIs, including cost, efficiency, and vacy. The court also noted the widespread use of questionable sales methods and pharmaceutical industry misconduct. ${ }^{82}$ IMS challenged the conconstitutionality of 22 M.R.S.A. $\S \S 1711-\mathrm{E}$, which "restrict[ed] the use of prescriber identifying information" in an effort to "decrease drug detailing that targets the prescriber, thus increasing decisions to prescribe lower priced drugs and decisions made on the basis of medical and scientific knowledge and driving down the cost of health care." ${ }^{83}$ The state also argued that 22 M.R.S.A. $\S 1711-E$ would enhance the effectiveness of other laws, including MRSA $\S 2698$-A; the court held that this was a legitimate governmental interest. ${ }^{84}$ Despite the legitimacy of this interest, the court held "that the provisions of the Maine Law that seek to restrict the use and disclosure of commercial information violate the free speech guarantee of the First Amendment." 85

\section{E. Proposed Federal Legislation: Is it Enough?}

The United States Congress has addressed the issue of pharmaceutical company gifts to physicians with the Physician Payment Sunshine Act of 2007 (PPSA), so named because it is intended to shed light on the relationship between the pharmaceutical industry and physicians. ${ }^{86}$ The PPSA was introduced in the Senate in September 2007; a similar bill was introduced in the House in March 2008. ${ }^{87}$ The sponsors of the PPSA intended that it would yield ''transparency' to such payments and ... . 'foster accountability by empowering consumers and other watchdogs."'88 The PPSA primarily addresses means of disclosure, rather than outright limits or bans on physician gifts. ${ }^{89}$ PPSA requires quarterly reports by "manufacturers of covered drugs, devices, or medical supplies under Medicare, Medicaid, or SCHIP [State Children's Health Insurance Program]."

The reports required by the PPSA must include physician's name, address, and facility with which the physician is associated, as well as the amount, date, and description of the payment. ${ }^{91}$ The description can fall into one of eight categories, including:

compensation; food, entertainment, or gifts; trips or

82. Id. at $160-66$.

83. Id. at 160 (quoting ME. REV. STAT. ANN. tit. $22 \S 1711-\mathrm{E}$ ) (2008)).

84. IMS Health Corp., 532 F.Supp. 2d at 175.

85. Id. at 182.

86. Kirby, supra note 41 .

87. Id.

88. Id.

89. Physician Payments Sunshine Act of 2007, S.2029, 110th Cong. (2007).

90. Id.

91. Id. 
travel; a product or other item provided for less than market value; participation in a medical conference, continuing medical education, or other educational or informational program or seminar, provision of materials related to such a conference or educational or informational program or seminar, or remuneration for promoting or participating in such a conference or educational or informational program or seminar; product rebates or discounts; consulting fees or honoraria; or any other economic benefit, as defined by the Secretary. 9

If the federal legislation is passed, it will preempt existing pharmaceutical industry disclosure laws in many states, which will eliminate inconsistency in this area of the law. ${ }^{93,94}$

\section{BACKGROUND: AMERICAN MEDICAL ASSOCIATION STANDARDS FOR PHYSICIAN GIFTS, FOOD \& DRUG ADMINISTRATION STANDARDS FOR ADVERTISING, AND INDIANA STATE MEDICAL GUIDELINES FOR BOTH}

\section{A. American Medical Association Standards}

In the early 1990s, the American Medical Association (AMA) developed its own standards to address the issue of physician gifts. ${ }^{95}$ The AMA Opinion states that gifts should only be accepted when they benefit a patient and are not too lavish. ${ }^{96}$ Certain gifts may be appropriate if they serve an informational purpose, including meals or textbooks. ${ }^{97}$ In addition, "[i]ndividual gifts of minimal value are permissible as long as the gifts are related to the physician's work (e.g., pens and notepads)." ${ }^{98}$ According to the AMA Opinion, subsidies from the industry should not be accepted directly or indirectly to pay for the costs of travel, lodging, or other personal expenses of physicians attending conferences or meetings, nor should sub-

92. Id.

93. Kirby, supra note 41.

94. In early 2009, the PPSA was reintroduced in the Senate, with some amendments. Maribel Rios, Physician Payments Sunshine Act Reintroduced for 2009 (Jan. 29, 2009), available at http://pharmtech.findpharma.com/pharmtech/News/Physician-PaymentsSunshine-Act-Reintroduced-for 2/ArticleStandard/Article/detail/577973?contextCategoryId $=35097$.

95. American Medical Association, Opinion 8.061- Gifts to Physicians from the Industry, adopted December 1990, http://www.ama-assn.org/ama/pub/category/4001.html (last visited Jul. 9, 2009).

96. Id.

97. Id.

98. Id. 
sidies be accepted to compensate for the physicians' time. ${ }^{99}$ Finally,

[n]o gifts should be accepted if there are strings attached. ${ }^{100}$ For example, physicians should not accept gifts if they are given in relation to the physician's prescribing practices. In addition, when companies underwrite medical conferences or lectures other than their own, responsibility for and control over the selection of content, faculty, educational methods, and materials should belong to the organizers of the conferences or lectures. ${ }^{101}$

\section{B. Food and Drug Administration Limitations: An Historical Perspective}

The Food \& Drug Administration (FDA) has also imposed advertising limitations on pharmaceutical companies. First regulated by the FDA, then the Federal Trade Commission, now FDA again, spending on direct-toconsumer (DTC) advertising rose from just $\$ 12$ million in 1989 to over $\$ 2.3$ billion in 2001. ${ }^{102}$ The Federal Food, Drug, and Cosmetic Act of 1938 (FDCA) contains one provision for pharmaceutical advertisements, which "requires simply that the advertisement include the drug's generic name and formula, and a brief summary describing the effectiveness of the drug and its risks." 103 This "brief summary" must include drug side effects and warnings. 104 "Second, the "fair balance doctrine" provides that the entire advertisement must present a balanced account of all clinically relevant information; the risks must be presented prominently and legibly so that the benefits are not unfairly emphasized." 105 Balancing information must be prominently mentioned in the ad so that patient-consumers can properly weigh the pros and cons of taking the drug. ${ }^{106}$ The advertising cannot be false or misleading and should be consistent with the drug's label. ${ }^{107}$

In addition, the FDA has created three "categories of prescription drug advertisements...: 1) reminder advertisements, 2) help-seeking or diseaseoriented advertisements, and 3) product-claim or indication advertisements." 108 Reminder advertisements show the drug name but do not provide information about the drug itself, such as pens, Post-Its, desk

99. Id.

100. Id.

101. Id.

102. Palumbo, supra note 17, at 423-24.

103. Id. at 428.

104. Id.

105. Id.

106. Id.

107. Id.

108. Palumbo, supra note 17 , at 428. 
calendars, or coffee mugs imprinted with a drug's name. ${ }^{109}$ Help-seeking or "see your doctor" advertisements are the opposite: they "typically describe the symptoms of a disease or condition, and encourage consumers to consult their physician to discuss treatment options, but do not mention the drug's name." 11 Since neither reminder advertisements nor help-seeking advertisements show consumers the effectiveness of a particular drug, the brief summary and fair balance requirements are inapplicable. ${ }^{111}$

Product-claim advertisements are a combination of the previous two types of advertisements, meaning they present the drug's name as a drug for certain medical symptoms. ${ }^{112}$ Because of this, product claim advertisements "must satisfy the brief summary requirements and maintain fair balance." 113

In 1999, the FDA decided that television advertisements must contain a "disclos[ure of] the product's major risks," which is presumably why the phrase, "if you experience an erection lasting more than four hours," has become part of the American lexicon. ${ }^{114}$ An ad must now include a tollfree phone number that consumers may call to receive more information; offer of further information in another medium ("see our ad in Soap Opera Digest"); a web address that has drug label information; and that consumerpatients may consult their physicians for more information. ${ }^{115}$

\section{Indiana State Medical Association Compliance and Guidance}

In Indiana, although gifts from the industry are not addressed by Indiana law, the Indiana State Medical Association defers to the AMA ethical standards in this area. 116

\section{IV: ANALYSIS: DO LIMITS AND BANS ON PHYSICIAN GIFTS AND ADVERTISING HELP OR HURT PATIENTS?}

The arguments on both sides of this compelling issue are comparably persuasive. On one hand, those opposing physician gift limits and bans consider industry guidelines sufficient to curb any inappropriate conduct by both pharmaceutical companies and physicians. In addition, some physicians are offended by the implication perpetuated by gift limits and bans that they are not prescribing drugs according to their patients' needs and

109. Id.

110. Id.

111. Id. at 428-29.

112. Id.

113. Id.

114. Palumbo, supra note 17 , at 431 .

115. Id.

116. Indiana State Medical Association, Legal Resources: Compliance and Guidance Documents, available at $\mathrm{http}: / / \mathrm{www}$. ismanet.org/legal/compliance_docs.htm. 
abhor the thought of further regulations that some fear could inhibit the free flow of information about new drugs.

In contrast, proponents of limits and bans on physician gifts cite ethical concerns and higher prescription drug costs as their primary criticisms of such gifts. This anti-pharm hysteria is widespread: Websites such as pharmedout.org and nofreelunch.org condemn the use of pharmaceutical company freebies to influence physicians' prescribing habits. A recent survey of patient-consumers revealed that many were opposed to pharmaceutical company gifts to physicians. ${ }^{117}$ Over $80 \%$ of respondents said that pharmaceutical companies should be prohibited from gifting physicians with free dinners and travel. ${ }^{118}$ In addition, over half of those surveyed thought that drug samples from pharmaceutical companies to physicians should be prohibited. ${ }^{19}$ Perhaps even more telling is that nearly $70 \%$ of respondents would support legislation requiring gift disclosure. ${ }^{120}$

The major concerns about the practice of pharmaceutical companies' gifts to physicians were enumerated by Dr. Ogan Gurel:

Unsustainable high cost (hence the massive layoffs that Pfizer announced in 2007)[;] [c]oncerns that marketing costs add to the cost of drugs passed on to patients[;] [e]thical concerns about inappropriate pressures being made on physicians with respect to gifts and other benefits being distributed by drug representatives[;] [t]he banning of pharmaceutical drug representatives from some medical campuses including Stanford, Henry Ford and Rush University medical centers. ${ }^{12}$

Further exploration of each issue is necessary to foster an understanding of the pros and cons of physician gift bans by state and federal legislatures.

\section{A. What Effect do Gifts have on Physicians' Prescribing Habits?}

In a study conducted in 2000 and published in the Journal of the American Medical Association, Ashley Wazana found that freebies and

117. The Prescription Project Survey, (June 2008), http://www.prescriptionproject.org/ assets/pdfs/Prescripton\%20Project\%20Survey_0618.pdf (last visited Jul. 9, 2009).

118. Id.

119. Id.

120. $I d$.

121. Ogan Gurel, MD, Counterdetailing: A Cure for a Pharmaceutical Addiction? (Mar. 17, 2008), http://www.midwestbusiness.com/news/viewnews.asp?newsletterID=19002 (last visited Jul. 9, 2009). 
honorariums had a significant impact on physicians' prescribing habits. ${ }^{122}$ Wazana found that when pharmaceutical companies paid for a physician to attend a conference, the physician prescribed that company's drugs 4.5-10 times more often. ${ }^{123}$ Physicians who answered that they "occasionally" accepted free meals from pharmaceutical companies "were 2.3 times more likely than other doctors to request that the sponsor's drug be added to a hospital formulary." 124 When physicians "often" accepted free meals from pharmaceutical companies, they "were 14 times more likely to do so."125 Despite the fact that many physicians admitted to some form of interaction with drug representatives, when asked if those representatives "fairly portray their product," $80 \%$ said no, while $75 \%$ said that the representatives "use unethical practices." who are easily swayed by free pizza or readily seduced by cunning drug representatives. Even the most well-intentioned doctor could fall prey to his or her subconscience after being subjected to freebies and drug ads. ${ }^{127}$

Despite what some physicians say, studies and social science show that pharmaceutical companies' gifts to physicians have a profound impact on physicians' prescribing habits. ${ }^{128}$ Dr. David Blumenthal suggests that "humans are vulnerable to a powerful, unconscious 'self-serving bias'; that is, they have trouble seeing themselves as biased when the bias serves their needs or advances their own perceived interests." 129 This means that even the smallest gifts from pharmaceutical companies may influence physicians' prescribing habits, since they may feel an obligation to reciprocate, either consciously or subconsciously. ${ }^{130}$ Blumenthal is skeptical that states' disclosure laws and gift limits will affect the relationship between pharmaceutical companies and physicians in the long run because such relationships are important to both parties: pharmaceutical companies need to sell their product, while physicians need to stay educated on cutting-edge drugs and therapies. ${ }^{131}$ He predicts recurring cycles of scandal and reform for the future.

122. Ashley Wazana, Physicians and the Pharmaceutical Industry: Is a Gift Ever Just a Gift?, 283 JAMA 373 (2000)

123. Id. at 378 .

124. Alex Roslin, Big Pharma's Pill Pushers - Why Americans Are Addicted to Expensive Prescription Drugs (Sep. 4, 2008), http://www.straight.com/print/160083\# (last visited Jul. 21, 2009).

125. Id.

126. Wazana, supra note 122 , at 377 .

127. David Blumenthal, MD, Doctors and Drug Companies, 351 NEw ENG. J. MED. 1885, 1887 (2004), available at http://content.nejm.org/cgi/reprint/351/18/1885.pdf.

128. See, eg., Wazana, supra note 122, at 377; Blumenthal, supra note 129, at 1887.

129. Blumenthal, supra note 129, at 1887 (citing Jason Dana \& George Loewenstein, $A$ Social Science Perspective on Gifts to Physicians from Industry, 290 JAMA 252, 252-5 (2003)).

130. Blumenthal, supra note 129 , at 1887.

131. Id. at 1889.

132. Id. 


\section{B. Are Pharmaceutical Representatives Qualified to Educate Doctors about New Drugs?}

Shahram Ahari, former drug representative for Eli Lilly, made a splash when he disclosed the dark side of pharmaceutical companies to sponsors of the PPSA and ABC News. ${ }^{133}$ Ahari alleged that drug representatives were hired on the basis of looks and charisma, and in his experience, the vast majority lacked any sort of science background. ${ }^{134}$ Ahari alleged that drug representatives are encouraged to use questionable sales tactics, "including how to exceed spending limits for important clients, being generous with free samples to leverage sales, using friendships and personal gifts to foster a 'quid pro quo' relationship, and how to exploit sexual tension."

There is also widespread concern in the medical community that bans and limits on physicians' interactions with drug representatives hurt patients because they limit the drug company's ability to convey information about new drugs and the latest innovations in medical research. Logic dictates that a prescribing physician cannot recommend a therapy or drug if he or she does not know it exists. Scott Lassman, PhRMA counsel, expressed such a concern: "[T] he new policies [are] a 'disservice to patients and physicians' because they keep doctors from interacting with sales representatives. 'The company sales representatives, in our point of view, have a lot of useful information on drug products and how to use them, and how not to use them." 136 This view is undoubtedly shared by many in the medical community.

While some drug representatives, such as Ahari, claim that they are instructed to participate in questionable sales tactics, a spokesman for Eli Lilly countered Ahari's claims:

'We think his examples are exaggerated. We have policies in place that allow us to engage in interactions with health care professionals at an appropriate level and they are intended to provide information about our products so that they will be able to make appropriate medical decisions for their patients. ${ }^{, 137}$

133. Marcus Baram, Ex-Drug Sales Rep Tells All, ABC News, (2009) http://abcnews.go.com/US/story?id=4438095\&page=1 (last visited Jul. 9, 2009).

134. Id.

135. Id.

136. Andrew Pollack, Stanford to Ban Drug Makers' Gifts to Doctors, Even Pens, N.Y. Times, Sep. 12, 2006, available at http://www.nytimes.com/2006/09/12/business/ 12drug.html?_r=1\&ref=business\&oref=slogin.

137. Baram, supra note 135. 
Meanwhile, Stanford University Medical Center prohibited even the smallest gifts to its physicians by pharmaceutical companies in an effort to reduce the influence that pharmaceutical companies have on its physician's prescribing habits. ${ }^{138}$

In response to the New York Times article, some physicians claimed that the Stanford limits were much too strict; in fact, some claimed that the AMA guidelines were too stringent as well. ${ }^{139}$ These physicians claim that the interaction between drug representatives and physicians is vital to informing their prescribing habits; others expressed outrage at the insinuation that a trinket, such as a pen or a measuring tape with a drug's name on it, would have a great effect on their prescribing habits. ${ }^{140}$

A key concern is the accuracy of the information provided by pharmaceutical representatives. One study, conducted by researchers at the University of California at San Diego School of Medicine, found that 12 of 106 statements made by pharmaceutical representatives, and later tested for accuracy, were false. ${ }^{141}$ This means that $11 \%$ of the statements contradicted information available to the representatives. ${ }^{142}$ Most frightening is the fact that the physicians to whom the information was given were not aware of the inaccuracy of the statements. ${ }^{143}$ Unsurprisingly, marketing material used by pharmaceutical companies often has a bias toward the company distributing it. ${ }^{144}$ In addition to providing skewed information, marketing material sometimes does not comport with FDA regulations "against promoting unapproved uses of drugs." representatives fail to accurately inform physicians about their product, coupled with questionable marketing materials suggests that pharmaceutical companies are not the best resource from which physicians should receive information about new drugs and therapies.

\section{Economic Concerns}

If these advertisements and gifts bring physicians to a level of awareness about new innovations in drug therapy without adverse influence on their prescribing habits, what is the harm? Look no further than your pock-

138. Pollack, supra note 138.

139. Reader Feedback: Is Limiting Industry Gifts a Smart Policy?, FiERCE HEALTHCARE, Sep. 15, 2006, available at http://www.fiercehealthcare.com/story/reader-feedback-is-limitingindustry-gifts-a-smart-policy2/2006-09-15.

140. Id.

141. M.G. Ziegler, et al, The Accuracy of Drug Information from Pharmaceutical Representatives, 273 JAMA 1296, 1296-7 (1995).

142. Id.

143. Id. at 1297.

144. Daniel Stryer \& Lisa Bero, Characteristics of Materials Distributed by Drug Companies, 11 J. GEN. INTERN. MED. 575, 579 ( 1996), available at $\mathrm{http} / / / \mathrm{www}$.springerlink. com/content/f625624628q5m333/fulltext.pdf.

145. Id. 
etbook. Most state legislatures have cited the growing costs of prescription drugs as a primary concern when enacting legislation banning gifts to physicians. ${ }^{146}$ While Massachusetts' approach is very specific and may come with some administrative costs, other states' disclosure laws may not get to the root of the problem. There is little evidence that requiring pharmaceutical companies to be accountable for their advertising expenditures reduces spending on physician gifts and other marketing avenues.

Marketing can have a drastic effect on how a drug is perceived. "The explosion in drug costs is directly proportional to marketing," says Alan Cassels, a pharmaceutical marketing researcher from the University of Victoria. ${ }^{147}$ Cassel further stated, "[p] when a certain company's drug rep has been in town because of a spike in that company's prescriptions.'

AstraZeneca, makers of Prilosec and Nexium, has exhibited "biochemical chutzpah" in its marketing of the drugs. ${ }^{149}$ The patent on Prilosec, the world's best-selling drug, ran out in 2001, prompting AstraZeneca to use a mirror image of the drug's isomers to create Nexium; the only difference between the two drugs is that "Nexium is 3 percent better at relieving symptoms." "150 [NTA: The previous citation was nearly a direct quote from the source; to simplify, I made is a direct quote]. Despite the lack of "significant clinical advance," Nexium was approved by the FDA that same year. ${ }^{151}$ Immediately after approval was granted, AstraZeneca launched an aggressive marketing campaign aimed at "getting doctors and patients to switch from Prilosec to... Nexium." ${ }^{152}$ As a result of this marketing blitz, Prilosec is still available over-the-counter, and costs consumers about $\$ 30$. $^{153}$ Its nearly identical counterpart, Nexium, costs about $\$ 200 .^{154}$ This demonstrates the remarkable effect that marketing techniques have on prescribers and patients.

Economic concerns of rising marketing and advertising expenditures of pharmaceutical companies cannot be overlooked. According to Jason Dana and George Loewenstein, "[g]ifts from the pharmaceutical industry contribute to the rapidly increasing cost of medical care, and more specifically, to the increase in expenditures on prescription drugs." ${ }^{155}$ This is sup-

146. See eg., Massachusetts Senate Bill No. 2863 (2008).

147. Roslin, supra note 124.

148. Id.

149. Robert Bazell, The Costly Side Effects of Nexium's Ad Blitz, NBC News (August 14, 2007), available at http://www.msnbc.msn.com/id/20249591/.

150. Id.

151. Id.

152. Id.

153. Id.

154. Id.

155. Jason Dana \& George Loewenstein, A Social Science Perspective on Gifts to Physicians from Industry, 290 JAMA 252, 252 (2003). 
ported by the doubling of prescription drug spending by patient consumers from 1995 to 2000 , with an increase of $17 \%$, attributable to physicians' prescribing more expensive drugs, in 2001. ${ }^{156}$ Pharmaceutical representatives tout the innovation of new drugs to physicians, which is supposed to offset or justify the increased cost of these new drugs. However,

[f]rom 1989 to 2000, the US Food and Drug Administration judged $76 \%$ of all approved new drugs to be no more than moderate innovations over existing treatments, with many being a modification to an older product with the same ingredient. In 2000, the average price of these standard-rated new drugs was nearly twice the average price of existing drugs prescribed for the same indications. ${ }^{157}$

Therefore, even though the overall effectiveness of most prescription drugs has not changed, the price of these drugs has increased far past the rate of inflation, resulting in no more bang for your buck.

Back in Massachusetts, medical conventions are being cancelled due to the new gift ban, causing some to wonder if the law is hurting the economy. The cancellation of a convention results in lost convention revenues for the city, as well as lost accommodation costs and entertainment expenditures.

Administrative costs induced by recordkeeping mandates may outweigh any perceived benefit of disclosure. The added costs and effort associated with such a recordkeeping requirement has spawned the introduction of companies seeking to capitalize on the gap in the market for physician gift registries. One company offers gift registry databases for physicians and pharmaceutical companies to maintain their compliance with recordkeeping requirements. This, of course, is not a complimentary service.

\section{Does Banning Free Drug Samples Hurt Patients?}

The availability of drug samples from pharmaceutical companies is also a concern. A 2000 study examined the effect of drug samples on physicians' prescribing habits. ${ }^{159}$ Survey participants, all physicians at University of Washington-based clinics, were presented with three different

156. Id. at $252-3$.

157. Id. at 253 .

158. John Gever, Medical Group Pulls Meeting from Boston over State Ethics Law, MEdPAGE TODAY (January 22, 2009), http:/www.medpagetoday.com/PublicHealthPolicy/ HealthPolicy/12567 (last visited Jul. 9, 2009).

159. Lisa D. Chew, et al., A Physician Survey on the Effect of Drug Sample Availability on Physicians' Behavior, 15 J. GEN. INTERN. MED. 478, 478 (2000). 
prescribing scenarios. $^{160}$ The first hypothetical patient was an insured woman with a simple urinary tract infection; the second was an uninsured man with hypertension. ${ }^{161}$ The third "patient" was an uninsured woman with "new onset depression." 162 The survey physicians were then asked what their preferred therapy was for each hypothetical patient. ${ }^{163}$ In the first scenario, only $1 \%$ of the doctors stated that their preferred therapy was ciprofloxacin; however, when drug samples were available, $17 \%$ of those doctors dispensed ciprofloxacin, regardless of the fact that $92 \%$ of them preferred another drug. ${ }^{164}$ The doctors justified their decision by reasoning that they wanted to immediately commence the patient's treatment and save the patient a trip to the pharmacy. ${ }^{165}$

In the second scenario, $91 \%$ of doctors selected a drug sample instead of their preferred therapy, citing prevention of extra financial burden on the uninsured patient. $^{166}$ In a follow-up scenario, where the same patient returned with the same symptoms but was insured, $69 \%$ of doctors said they would write a prescription for the drug sample instead of switching the patient's medication, while $88 \%$ said they would write a prescription for their initial preferred therapy. 167

Finally, for the third "patient," an uninsured woman suffering from depression, $69 \%$ of doctors preferred a selective serotonin reuptake inhibitor. $^{168}$ Of the $82 \%$ of respondents who said they would dispense a drug sample, $49 \%$ would dispense a drug sample inconsistent with their preferred therapy. ${ }^{169}$ As in the second scenario, most doctors cited the need to ease the financial burden on the uninsured patient as justification for their behavior 170

Researchers stated that their "most disturbing finding [was] that the presence of drug samples may influence physicians to dispense or prescribe drugs that differ[ed] from their preferred drug choice."171 This ultimately means that compliance with industry guidelines for dispensing certain therapies for certain illnesses or symptoms is compromised. ${ }^{17}$

While it would seem that drug samples help less fortunate patients, by offering doctors a free alternative to prescription medicine, a study by researchers at Harvard Medical School and Cambridge Health Alliance indi-

160. Id. at $479-80$.

161. Id. at 479 .

162. Id.

163. Id.

164. Id. at 480 .

165. Chew, supra note 162 , at 480.

166. Id. at 481 .

167. Id.

168. Id.

169. Id.

170. Id.

171. Chew, supra note 162 , at 482 .

172. Id. 
cated that most free drug samples go to affluent patients. ${ }^{173}$ This is because poor patients do not often visit the doctor's office due to the expense of keeping an appointment. ${ }^{174}$ The study found that only $28 \%$ of patients receiving drug samples were below the poverty level. ${ }^{175}$ According to Sarah Cutrona, MD, lead author of the study, "“[d]octors like to give free samples, and patients like to get them, and no one wants to think of them as a powerful marketing tool of the drug industry... But that's what samples are. And what they really are not is a safety net for the needy." 176 This is contrary to the opinion of Ken Johnson, vice-president of PhRMA, who claims that drug samples help patients and "often lead to improved quality of life for millions of Americans, regardless of their income."177 Yet another doctor asserts that the drug samples do not go to needy patients, but usually go home with physicians and their employees instead. ${ }^{178}$ It appears that drug samples do help some patients, but not those who need them most.

\section{E. Ethical Concerns}

Florida physician James P. Orlowski refuses to let pharmaceutical companies influence the way he prescribes medication to patients; he has a self-imposed ban on drug representatives entering his Tampa Bay office, rejecting all industry gifts, even pens. ${ }^{179}$ Although Orlowski would prefer that Congress and the state legislatures refrain from getting involved, he believes that the high visibility of the legislation may open up his colleagues' eyes to this rampant problem. ${ }^{180}$

Indeed, physicians can be inundated with gifts; one anonymous member of the National Physician's Alliance

turned down 12 free breakfasts, 18 lunches, 16 branded pens, a branded eyeglasses cleaner, two branded pen lanyards, branded pill holders, Post-it Notes, notepads, a pocket Physicians Desk Reference, correction paper strips, a coffee mug, a poster, a hig-

173. Barbara Basler, Free Drug Samples Help the Well-Off More Than the Poor, THE PRESCRIPTION PROJECT, Jan. 4, 2008, available at http://www.prescriptionproject.org/assets/ pdfs/Basler_AARP_samples_Jan-2008.pdf.

174. $I \bar{d}$.

175. Id.

176. Id.

177. Id.

178. Howard Brody, MD, The Company We Keep: Why Physicians Should Refuse to See Pharmaceutical Representatives, 3 ANN. FAM. MED. 82, 84 (2005), available at http://www.annfammed.org/cgi/reprint/3/1/82.

179. Kris Hundley, Doctor Combats Pull of Drug Reps, St. Petersburg Times, Dec.27, 2007, available at http://www.sptimes.com/2007/12/27/Business/Doctor_combats pull o.shtml.

180. Id. 
hlighter, a diagnostic manual, a giant clip-refrigerator magnet, a ruler, a water-oil globe, a History of Viagra book and a Viagra soap dispenser - in only a monthand-a-half. ${ }^{181}$

This inundation of gifts has prompted some physicians to call for the profession-wide refusal of pharmaceutical company gifts. ${ }^{182}$ Dr. Howard Brody ${ }^{183}$ frames the ethical argument in the following way:

1. As a matter of professional integrity, I claim that I ought to behave in accord with certain principles. 2 . Empirical evidence shows that I am highly likely to behave in ways contrary to my professional principles when I keep company with [pharmaceutical representatives]. 3. My professional responsibilities do not require me to keep company with [pharmaceutical representatives]. 4. If, therefore, I choose to continue to keep company with [pharmaceutical representatives], I cannot claim that I truly wish to adhere to those professional principles. ${ }^{184}$

Brody goes on to explain that empirical evidence demonstrates not only that physicians are influenced by pharmaceutical representatives, but that they do not realize they are being influenced. ${ }^{185}$ He also says that spending time with pharmaceutical representatives is often a waste of time, and that most physicians do not allow themselves time to later check the representative's statements for accuracy and bias. ${ }^{186}$ The only way for the physicianpharmaceutical representative relationship to be an effective educational tool would be "[for physicians to] spend time with reps in a manner that preserves professional integrity[, which] would require both refusing to accept their gifts and spending a great deal of valuable time double-checking their information." $"$ Brody thinks that physicians could spend their time more wisely. ${ }^{188}$

The primary ethical concern regarding pharmaceutical company gifts to physicians is whether the gift clouds the physician's judgment in pre-

181. Id.

182. Brody, supra note 181 , at 82 .

183. Id. Brody is a professor and director for the Institute for the Medical Humanities, University of Texas Medical Branch at Galveston. He is also the author of Hooked: Ethics, the Medical Profession, and the Pharmaceutical Industry (Rowman \& Littlefield 2007).

184. Brody, supra note 181 , at 83.

185. Id. at 82 .

186. Id.

187. Id. at 84 .

188. Id. at 85 . 
scribing medicine. Nurse practitioners with prescribing privileges are not immune to this phenomenon either. ${ }^{189}$ The problem is that "gifts entice health professionals into relationships that subtly call for reciprocity, and have been shown to influence prescribing behaviors." 190 Some also fear that doctors overprescribe medications, rather than offering cheaper alternatives to prescription drugs. ${ }^{191}$ For example, doctors may prescribe hormone replacement therapy for menopausal women, when simply shedding a layer of clothing and getting a good night's sleep might help alleviate their symptoms, sans drug. ${ }^{992}$

Ethical concerns are also illuminated when considering advertisements in medical journals. ${ }^{193}$ Medical journals have multiple obligations that may conflict. ${ }^{194}$ Such obligations include "the independence of journal reports[both] to their professional subscribers and by extension to the public. These obligations could conflict because unbiased reporting is expected."195 When journals publish advertisements, they are making a choice to promote a particular drug due to their financial obligations, when independent judgment may not dictate that particular choice. ${ }^{196}$

\section{G. First Amendment Issues}

Yet another issue that concerns opponents of physician gift bans is whether it impedes on the exercise of free speech. ${ }^{197}$ In 1976, the United States Supreme Court struck down a Virginia statute that prohibited Virginia pharmacies from advertising their drug prices. The court reasoned that the advertisements had value as commercial speech. ${ }^{198}$ Advertisements from pharmaceutical companies are generally regarded as commercial speech, rather than personal speech, which is regarded as a higher form of speech, and thus more protected. ${ }^{199}$ In order to pass Constitutional muster, a restriction on commercial speech must have a substantial governmental interest that is directly advanced by the restriction. ${ }^{200}$ In addition, the re-

189. Charlene L. Stokamer, Pharmaceutical Gift Giving: Analysis of an Ethical Dilemma, 33 JONA 48, 48 (2003).

190. Id.

191. Id.

192. Id. at 50 .

193. Id.

194. Id.

195. Stokamer, supra note 192 , at 50.

196. See eg., id.

197. Aaron S. Kesselheim, MD, JD \& Jerry Avorn, MD, Pharmaceutical Promotion to Physicians and First Amendment Rights, 358 NEW ENGL. J. MED. 1727 (2008), available at http://content.nejm.org/cgi/content/full/358/16/1727.

198. Id. at 1728. (referring to and citing Virginia State Board of Pharmacy v. Virginia Citizens Council, Inc., 425 U.S. 748 (1976)).

199. Kesselheim, supra note 201, at 1728.

200. Id. 
striction must be no more broad than necessary to accomplish its goals. ${ }^{201}$

Can state statutes limiting or banning physician gifts survive this intermediate level of scrutiny? Some argue that limitations on marketing habits of pharmaceutical companies "can improve prescribing decisions and protect the public's health." 202 It appears, however, that new state legislation preventing pharmaceutical companies from using prescribing habit information will pass constitutional muster, at least according to the First Circuit. $^{203}$ The statute there, however, limited pharmaceutical companies' access to information mined for the purpose of tailoring marketing efforts to specific physicians. ${ }^{204}$ It remains to be seen whether restrictions on pharmaceutical company gifts to physicians will be supported by the courts.

\section{H. What is the Best Solution?}

Limits and bans on such gifts are just one way to combat the effect of pharmaceutical industry influence on physicians. While an outright ban, such as the one implemented in Massachusetts, seems harsh, there is little evidence that lesser limitations, such as those implemented in West Virginia, have had any great effect on this problem.

Indiana's biggest pharmaceutical company, Eli Lilly, has already taken proactive steps to anticipatorily comply with the PPSA. The PPSA, however, only requires reporting and disclosure of gifts; it does not limit such gifts to physicians. An outright ban, such as the Massachusetts ban, would likely be more effective at curbing the influence that uninformed (though perfectly coiffed) drug representatives have on physicians who should know better.

The PPSA and the Massachusetts ban are on opposite ends of the spectrum, with Minnesota's limits in between. While a happy medium seems favorable, it is evident that drastic measures will need to be taken in order to reverse the troubling trend that is unfolding in the health care industry because of pharmaceutical companies' gifts to physicians. There appears to be a fine line between educating physicians about new pharmaceutical therapies and influencing them to write a prescription that they normally would not, if not for external factors.

As far as institutional policies which restrict contact between pharmaceutical representatives and physicians go, one study has suggested that physicians who had been trained on the policy after it had taken effect were much more skeptical of statements made by pharmaceutical representa-

201. Id.

202. Id. at 1731 .

203. Kevin B. O'Reilly, New Hampshire Ban on Sale of Prescribing Data, AMER. MED.NEwS, Dec. 22, 2008, available at http://www.ama-assn.org/amednews/2008/12/ 22/prsc1222.htm.

204. Id. 
tives. $^{205}$ A restrictive policy, however, did not affect whether a physician would meet with the pharmaceutical representative. ${ }^{206}$ This study seems to indicate that restrictive policies in medical institutions do affect the way physicians think about their interactions with drug companies; ${ }^{207}$ a stateimposed policy regarding gifts and disclosure may have a similar effect.

The FDA advertising limits, however, are unnecessarily stringent. Since television viewers are so inundated with parades of atrocious side effects so frequently, risks of warnings and side effects can often fall on deaf ears. Some side effects may be minimal, but because of their prominent placement in drug commercials, it also could cause some viewers to be too terrified to try a drug that could help them more than hurt them. The FDA advertising limits create an advertising environment for prescription drug advertisers which forces pharmaceutical companies to produce the same bland commercials with the same frightening side effects. This likely does not aid in promoting a product as efficiently as could be done if the FDA's requirements were not so limiting. If pharmaceutical companies could realistically portray their products, rather than show people walking hand-in-hand across a field of flowers whilst discussing their genital herpes, it may create more of a desire in consumer-patients to become educated about the product. The advertisement restrictions are unfair in the sense that they prohibit the pharmaceutical companies from flaunting the positive aspects of their products and instead force them to recite a laundry list of horrendous side effects.

\section{CONCLUSION}

Studies have shown that gifts from pharmaceutical companies, pharmaceutical advertisements, and information tendered from pharmaceutical representatives may have an effect on physicians' prescribing habits. Economic and ethical concerns are at the heart of the issue of pharmaceutical company influence. States have attempted to curb this influence through legislation designed to limit or ban gifts to physicians and mandate disclosures for certain types of gifts. For most state legislation, it is too early to tell whether such legislation will have any effect on physicians' prescribing habits and limiting pharmaceutical company influence. There has been very little litigation relating to the state statutes. The PPSA, if passed, will provide consistency in disclosure and recordkeeping, while allowing states to maintain stricter standards if they wish. Some physicians are concerned that they will be unable to obtain information about new drugs and thera-

205. George D. Comerci, Long-Term Effects of Restricting Residents' Contact with Drug Representatives, 7 AAP GRAND RouNDS 32 (2002), available at http://aapgrandrounds. aappublications.org/cgi/reprint/7/3/32.

206. Id.

207. Id. 
pies once state and federal legislation goes into effect. There is evidence, however, that information disseminated by pharmaceutical companies can be biased and even inaccurate.

The key to global peace on this issue appears to be a balancing of the free-flowing dissemination of information between pharmaceutical companies and physicians regarding new drug information and therapies with the influence of gift-giving on physicians' prescribing habits. Disclosure plays a key role in achieving this balance, as is evident in the implementation of recordkeeping and disclosure statutes in states across the nation.

The best way to prevent pharmaceutical company influence on physicians remains to be seen. Once the state plans have been in effect for awhile, it will be easier to see what is most effective at curbing this undue influence. For now, it is important for doctors to realize that, no matter how esteemed and educated, they are not immune to pharmaceutical company influence. Awareness of the problem will lead to a better solution. Only then will fictional Marie, and the rest of the American public, be able to rest easy, confident that their doctors are making well-informed, independent decisions solely for the health of their patients. 